\title{
Deutsche Röntgengesellschaft verleiht den Promotionspreis 2021 an Dr. Quirin Strotzer
}

Die Deutsche Röntgengesellschaft hat Dr. Quirin Strotzer vom Universitätsklinikum Regensburg ihren diesjährigen Promotionspreis verliehen. Ausgezeichnet wurde Dr. Strotzer für seine Arbeit „Deep Brain Stimulation: connectivity profile for bradykinesia alleviation“.

Dr. Quirin Strotzer hat den Promotionspreis 2021 der Deutschen Röntgengesellschaft verliehen bekommen. Auf dem 102. Deutschen Röntgenkongress stellte Dr. Strotzer mit seiner ausgezeichneten Arbeit „Deep Brain Stimulation: connectivity profile for bradykinesia alleviation“ neue Erkenntnisse vor, die dabei helfen könnten, die Mechanismen der tiefen

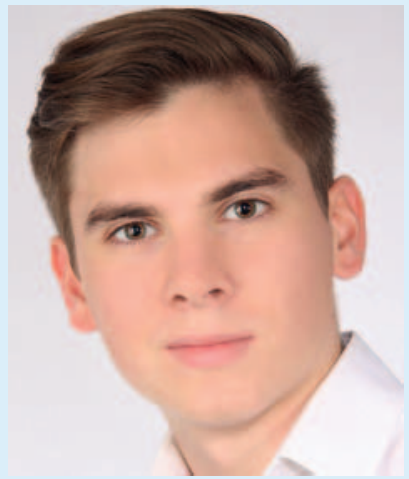

Dr. Quirin Strotzer @ privat
Hirnstimulation (THS) besser zu verstehen und die Zielpunktplanung für verschiedene Manifestationsformen des Morbus Parkinson und andere Erkrankungen zu verbessern.

Die Deutsche Röntgengesellschaft verleiht seit 2012 einen Promotionspreis, um wissenschaftlich engagierte Studentinnen und Studenten sowie Medizinerinnen und Mediziner zu motivieren und zu fördern. Pro Jahr werden bis zu 3 Promotionsarbeiten ausgezeichnet. Im Fall einer Auszeichnung der eingereichten Arbeit wird diese als Originalarbeit in der Fachzeitschrift RöFo veröffentlicht. Der Promotionspreis ist mit $1000 €$ dotiert. 